\title{
Genetically engineered lymphocytes in metastatic melanoma: TIL 1383I TCR transduced T-cells are detectable after infusion
}

\author{
Courtney Regan ${ }^{*}$, Michael Nishimura ${ }^{1}$, Ann Lau Clark', Kelly Moxley', Gina Scurti ${ }^{1}$, Vladimir Slepushkin², \\ Andre Roy ${ }^{2}$, Kathy Schonely², Boro Dropulic², Joseph Clark' \\ From Society for Immunotherapy of Cancer 28th Annual Meeting \\ National Harbor, MD, USA. 8-10 November 2013
}

\section{Background}

Previous studies in adoptive T-cell transfer have suggested that persistence of the transduced T-cells is central to making this therapy a viable option. Understanding the behavior of tumor-reactive T-cells in cancer patients and measuring persistence are two objectives in a phase I clinical trial using TCR TIL 1383I transduced T cells in stage IV melanoma patients.

\section{Methods}

Peripheral blood mononuclear cells (PBMCs) were isolated from a melanoma patient, activated with antihCD3 with rhIL2 and rhIL15, transduced with lentivirus encoding the TIL 1383I TCR, and expanded to treatment numbers. $2 \times 10^{8}$ transduced cells were suspended in $5 \%$ human albumin and infused over 30 minutes. The infusion was preceded by lymphodepletion with fludarabine and cyclophosphomide and followed with low dose IL-2 for one week. A modified CD34 cassette in the vector enabled monitoring of the transduced $\mathrm{T}$ cells in the patient's PBMC post-infusion. PBMC were collected from patient on days $1,3,5,7,14,25$, and 35 . The presence of transduced $\mathrm{T}$ cells at each timepoint was measured by staining with anti-CD34 mAb and analyzed using a BD LSRFortessa flow cytometer.

\section{Results}

Transduced T cells were detected in the patient's blood at day 25 post infusion. $1.45 \%$ of the patients $\mathrm{T}$ cells were TIL 1383I TCR transduced T-cells. We estimate that at least $10 \%$ of the infused TIL 1383I TCR transduced $\mathrm{T}$ cells were present after 4 weeks.

\section{Conclusion}

Previous studies with TIL suggest better T-cell engraftment, persistence, and therapeutic efficacy with homeostatic proliferation after lymphodepletion. Out results confirm that the infused TIL 1383I TCR transduced T-cells could be detected 4 weeks after infusion. Localization of genetically engineered $\mathrm{T}$-cells and ensuring their activation and function is of value in anti-tumor T-cell therapy.

\section{Authors' details}

${ }^{1}$ Cardinal Bernadin Cancer Center, Loyola University Medical Center, Maywood, IL, USA. ${ }^{2}$ Lentigen Corporation, Gaithersburg, MD, USA.

Published: 7 November 2013

doi:10.1186/2051-1426-1-S1-P31

Cite this article as: Regan et al:: Genetically engineered lymphocytes in metastatic melanoma: TIL 1383I TCR transduced T-cells are detectable after infusion. Journal for ImmunoTherapy of Cancer 2013 1(Suppl 1):P31. 